\title{
Engagement in Online Learning: A Case Study on MBA Students Undertaking Professional Internships
}

\author{
Hanna Yakavenka and Riccardo De Vita \\ University of Greenwich, Business School
}

\section{Introduction}

This study is a critical evaluation of the online interactions of learners registered on a professional development course which will contribute to the general academic debate and assist in the design of a specific course. From a theoretical point of view, existing studies reported that one of the major obstacles to successful online learning is the isolation of learners (McDonald et al., 2005). A detailed visualization and analysis of online engagement and communication is discussed through the use of appropriate methodologies. The course under investigation was recently reviewed and stronger emphasis was put on online activities to leverage the properties of Moodle. An analysis of students' engagement and performance is deemed extremely relevant for the course and the improvement of the overall learning experience of its participants.

\section{Course Settings}

The course under investigation is a 60 credit postgraduate (PG) level module titled Professional Practice. A year long course was introduced in 2009 to provide a learning platform, tutor support and assessments for MBA International Business students while undertaking management level internships (often abroad).

Until last year, when the university migrated to Moodle, the course was operating on WebCT and managed by one member of the academic staff. With limited learning materials on VLE and three assignments clustered at the end of the year, there was insufficient intermediate evidence that students were engaged in learning. It was also observed that most of the students avoided any sort of interaction with peers and/ or tutors and tended not to raise questions even if something was unclear. Because the students were working, there was no formal face-to-face (F2F) teaching on the course and assessment consisted of three summative assignments, two of which could be submitted midcourse for formative feedback where students were asked to report purely on their internship activities. The core element of the summative assessment was a report at the end of the year where students were asked to reflect on their learning and professional development through the internship, while taking into consideration their previous learning on the taught element of the programme. In the main, students did not seek feedback on draft submissions, resulting in the majority of them finding the summative assessment challenging, resulting in rather low overall results. 


\section{Course Participants}

The majority of students did not come with a social sciences background, with their educational systems having less emphasis on research, critical thinking and reflective enquiry in their curricula compared to the UK higher education sector. Most of the students had different cultural backgrounds and the academic team observed the tendency of students to network with people of the same ethnicity, with less frequent communication with learners from different countries. Investigating the reproduction of a similar behaviour online is one of the key objectives of this paper.

Table 1 provides basic information about the cohorts of students analysed in this study. Cohort One (September 2010 starters) interacted on WebCT. When, in 2011, the Business School moved to Moodle, January 2011 starters (Cohort Two) used both WebCT and the new VLE. Cohort Three (September 2011 starters) is undertaking the course fully on Moodle.

\begin{tabular}{|c|c|c|c|c|c|c|c|}
\hline $\begin{array}{c}\text { Group } \\
\text { Start of } \\
\text { internship) }\end{array}$ & N. & \multicolumn{2}{|c|}{ Gender } & \multicolumn{2}{c|}{ Age } & $\begin{array}{c}\text { Average on } \\
\text { Professional } \\
\text { Practice) }\end{array}$ & $\begin{array}{c}\text { Average on taught } \\
\text { elements of the } \\
\text { Programme }\end{array}$ \\
\hline & & $F$ & $M$ & $21-25$ & $26-32$ & & \\
\hline $1(09 / 10)$ & 27 & 5 & 22 & 16 & 11 & 52.8 & 60.0 \\
\hline $2(01 / 11)$ & 32 & 6 & 26 & 19 & 13 & 56.3 & 59.3 \\
\hline $3(09 / 11)$ & 25 & 12 & 13 & 18 & 7 & NA & 56.9 \\
\hline Total & 84 & 12 & 61 & 53 & 31 & 54.7 & 58.8 \\
\hline
\end{tabular}

Source: Authors' elaboration

\section{Description of Online Interactive Activities in the Course}

To address the challenges faced by students when completing the assessment tasks, the following two on-going online activities have been put in place:

Learning logs (open between a learner and a tutor only) expects learners to map (via regular Moodle entries) their learning experiences during placement while trying to critically analyse and synthesise developments of practice locally, nationally or internationally as well as report on their continuing professional development. Logs are only visible to learners and tutors and serve as a tool to get individual support and clarifications when required.

- Weekly reflective blogs (open to all peers) expect learners to reflect on their individual learning and experience at a placement. This experience is designed to provide an opportunity to promote reflection and interaction among peers who go through similar experiences. Being an open space any learner can choose what to contribute and who to respond to when there are similar learning experiences taking place. Tutors can opt to engage in the discussion, but would not respond on an individual basis; instead they would try to provide general comments applicable to all the learners.

Both activities take place on the course Moodle platform enabling students' engagement into the learning process in a more individual and flexible manner as well as providing a channel of communication with 
peers and tutors. The benefits of peer or interdependent learning arise from the sharing of ideas, experiences and knowledge among learners (Boud et al., 2001). Such experience provides individuals with a feeling of belonging, while being flexible, when the whole group benefits from the knowledge sharing intensifying learning opportunities. Being a PG course, it is expected that the responsibilities for learning, teaching and feedback are reciprocal between learners and tutors. The students are encouraged to provoke discussion through their posts, to make others want to read, question and debate, resulting in the development of critical reflection skills and maximising the learning experience overall. Within this framework, the tutors adopt the role of professional advisors, reacting when required by the learning process.

\section{Evaluation of Online Engagement}

Given the focus of this study on online interaction and communication exchanges, an appropriate methodological approach was required. A research methodology particularly suitable to detect and address the challenge of exclusion of some learners while communicating online is Social Network Analysis - SNA (Reffay and Chanier, 2003). To fruitfully apply SNA in this context, 'relational' data describing collaborative learning practice was required.

Both WebCT and Moodle allow students to generate personal posts visible online to the whole community of learners. It was therefore possible to map online interaction between learners: specifically learner $\mathrm{i}$ is conceived to be connected with learner $\mathrm{j}$ when $\mathrm{i}$ was commenting on the post of $\mathrm{j}$. Analysing all the posts and comments received it was possible to generate the overall communication network depicted in Figure 1.

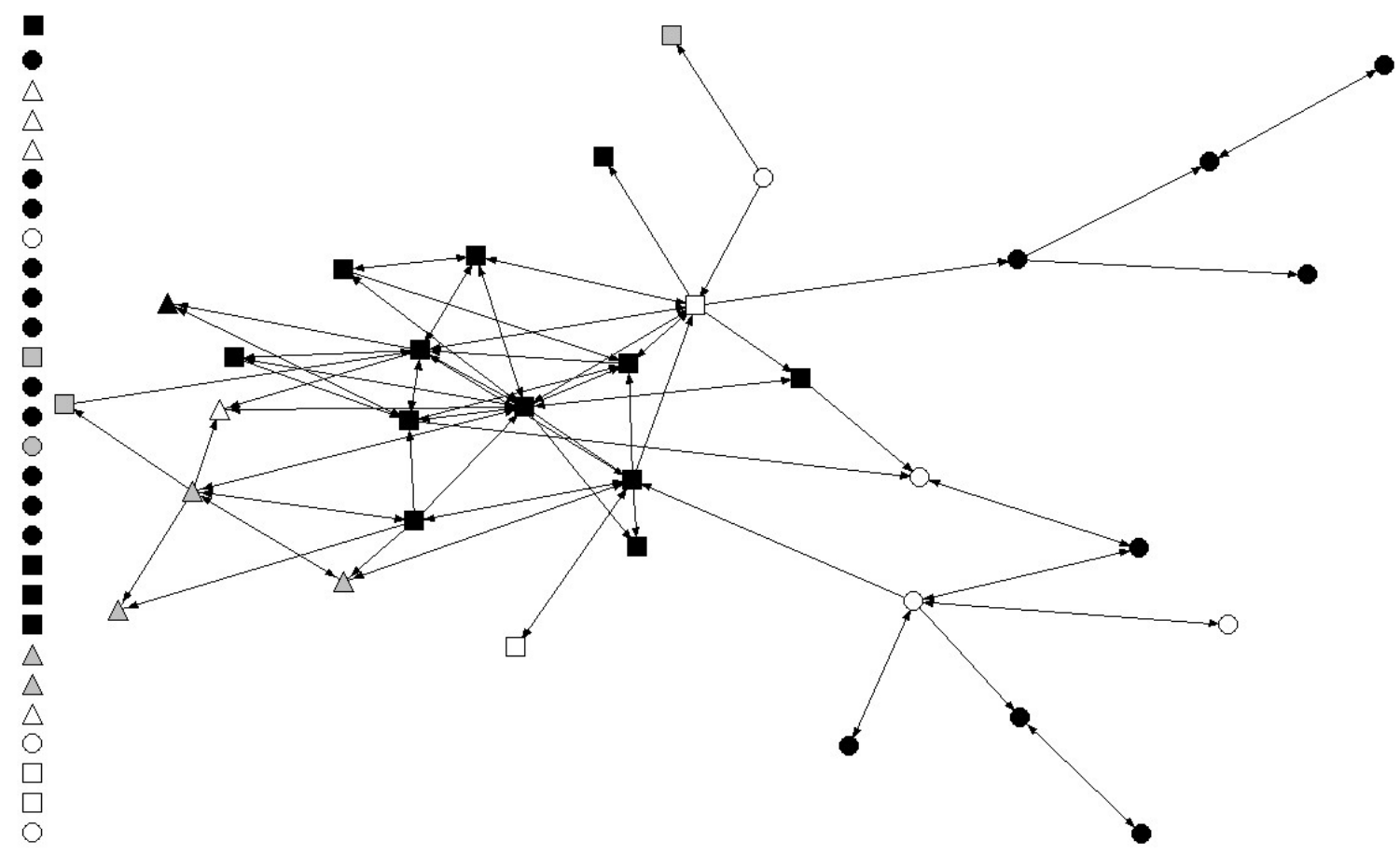

Figure 1 Bar-chart showing technologies to which students were directed to their lecturers Source: Authors' elaboration

- The network depicts only those students who successfully completed the course or are still registered. Instructors, who were marginally involved in specific moments of the course, are also not displayed. Some messages, not relevant for the purpose of this study (invitations to connect on a specific social network), were not considered. 
The network clearly shows that online engagement is an 'issue' for the course under investigation. Not all the students are active online in terms of receiving or sending comments to peers.

To detect the tendency toward the creation of culturally homophilous groups, learners in Figure 1 are coloured according to their ethnicity (black is Indian, grey is African while other ethnicities are represented in white), while the shapes identify the three different cohorts. By conducting qualitative analysis of the posts it was clear that students tended to communicate more with peers of the same ethnicity and cohort. While this result is unsurprising (students from the same cohort would have shared the online learning platform for longer, thus naturally increasing the likelihood of communication between them), it confirms the importance of an offline interaction as a prerequisite for successful online communication. Furthermore this visualization highlights the tendency toward clustering based on ethnicity and confirmed by the teaching staff observing in-class interactions.

Further investigation of network relationships allowed exploration of the associations between network position and performance on the course. While one could expect the amount of communication with peers to be associated with performance, it was not possible to confirm a similar hypothesis. The amount of comments received, for example, was not found to be statistically significant predictors of a learner's performance in the course. The only factors being associated with improved performance in the course were online engagement (e.g. reading blogs, posting messages) and performance in the taught components of the programme.

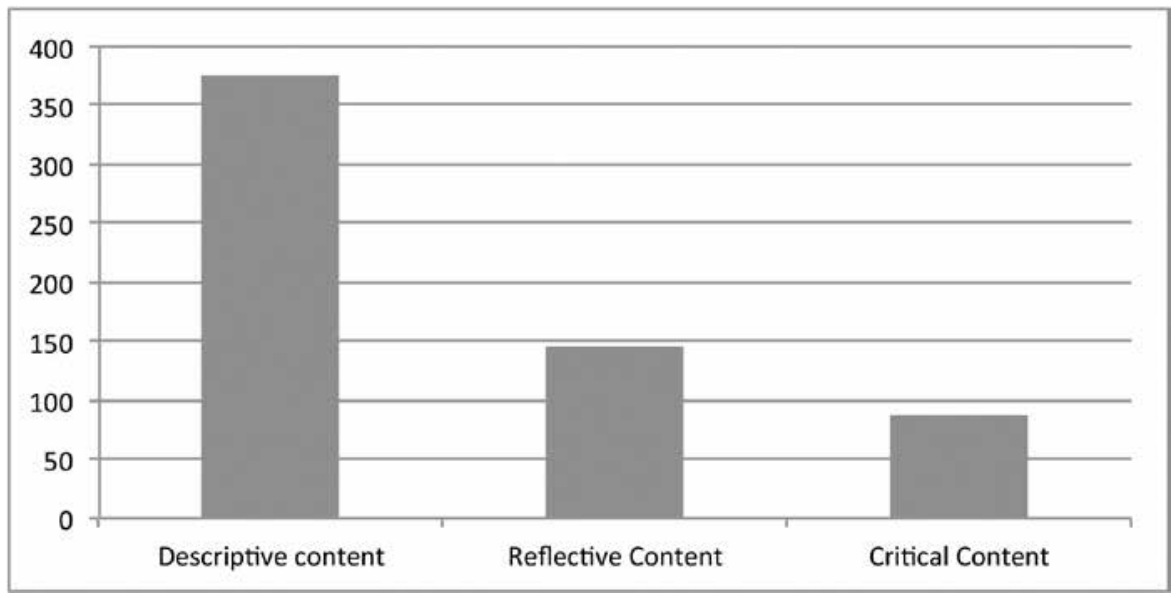

Figure 2. The Nature of Online Messages (608 Messages Analysed)

Source: Authors' elaboration

Figure 2 clearly shows that the majority of communication taking place online was of a descriptive nature. Moreover, only a limited number of messages had explicit references to other sources of knowledge (e.g. books, online materials, a peer's comment), illustrating the lack of integration of the online communication with the past learning experience of the learners. It is therefore possible to assume that it is the actual quality of the interaction that explains the absence of a positive influence between peer learning and performance on the course.

- The network depicts only those students who successfully completed the course or are still registered. Instructors, who were marginally involved in specific moments of the course, are also not displayed. Some messages, not relevant for the purpose of this study (invitations to connect on a specific social network), were not considered. 
An in depth understanding of these results called for further analysis, with 608 messages exchanged online being qualitatively coded and preliminary analysis done based on descriptive, reflective or critical content (Figure 2) which can take different nuances (e.g. Browne and Freeman, 2000; Barnett, 1997), but similar classifications are important and relevant learning opportunities need to be in place if students are to be effectively engaged in learning and appropriate teaching practices developed (Rowland, 2001).

\section{Enhancing Learners' Experience on a Practice Oriented Course}

\section{Lessons Learned}

When students are spread around geographically conventional F2F course delivery has severe limitations which technology can overcome by engaging learners and enabling them to share their experiences more effectively. Setting this up is complex and a considerable amount of up-front work is required from Webbased course designers, but students do seem to prefer the convenience and flexibility of studying online. As noted by Alley and Jansak (2001, p. 3) "making a class 'happen' in a web-based environment is so new and different that neither broad principles nor narrowly prescriptive practices are helpful when we sit at a computer and try to reinvent our teaching in this new environment". The Moodle platform allows the peer learning experience to occur independently of the 'distances' between learners, attracting and connecting them based on the similarity of work experience, internship problems, interest of their research, and learning preferences. Ideas are best when they are tested during discussions with others who are going through a similar process (Boud et al., 2001). Working with others can also facilitate reflection, an individual's learning, and the ability to recognize opportunities (Moon, 1999). Knowledge is constructed by all participants in the process and education is only effective if contributors take responsibility for their own learning. This study did highlight that collaboration and effective knowledge sharing online is far from straightforward, with learners at risk of being isolated. This illustrates the vital importance of having appropriate systems in place that promote the engagement and improve the quality of online interactions.

\section{Proposed actions}

In order to provide a more effective learning experience on the course under investigation and increase the engagement of students, it is proposed to leverage the potentiality of other Moodle tools (e.g. group wikis) combined with a stronger involvement of the academic team via asynchronous dialogue with tutors and peers. To help students progressively familiarize themselves with online tasks and to support them in becoming more critical, self-reflective and provide feedback, the proposition is to encourage students to organise themselves into working groups (supervised by a dedicated tutor) either based on the characteristics of their internships, industry sectors or job positions. Group wikis will be created and students will be expected to contribute to them regularly. In order to have a more focused and subject related discussion, tutors could initiate a discussion on a specific topic and then take an observer's role allowing the learners to develop it.

Existing Moodle features will be maintained: blogs being visible to the rest of the cohort, enabling comments and suggestions from students in other groups, reducing the risk of some students feeling isolated while being 'locked' in a sub-group. This should motivate learners not to simply share their ideas, based on readings and/or experiences, but also to constructively criticise the 'posts' of their peers using thematic contributions to wikis. The intention is to generate an academically grounded communication exchange with learners' posts supported by real life experiences and/or literature. Tutors would monitor progress of the groups by encouraging a knowledge-based dialogue via formative feedback. 
In order to further link the activities with the assessment it is proposed that students would regularly complete smaller tasks for feedback and discussion, which would eventually contribute to a final summative task - individual reflective report. These smaller tasks could be incorporated into existing online activities and newly proposed wikis in such a way that learners would be able to test their ideas by discussing them with their peers before presenting them more formally to the tutors. Such an approach has positive implications for any practice-led course where the emphasis is on solving real problems and developing solutions in application to real scenarios - in this case individual professional practice experiences. Within these learning communities it is expected that students will be providing feedback to each other via synchronous / asynchronous communication channels and contributing to an on-going group professional developmental process.

\section{References}

Alley, L. R., \& Jansak, K. E. (2001). The Ten Keys to Quality Assurance and Assessment in Online Learning. Journal of Interactive Instructional Development, 13(3), 3-18.

Barnett, R. (1997). Higher Education: a Critical Business. Buckingham: SRHE and Open University Press.

Boud, D., Cohen, R., \& Sampson, J. (2001). Peer learning in Higher Education: Learning from Each Other. London: Kogan Page Inc.

Browne, M., \& Freeman, K. (2000). Distinguishing Features of Critical Thinking Classrooms. Teaching in Higher Education, 5(3), 301-310.

McDonald, B., Noakes, N., Stuckey, B., \& Nyrop, S. (2005). Breaking Down Learner Isolation: How Social Network Analysis Informs Design and Facilitation for Online Learning. Paper presented at the Annual Meeting of the American Educational Research Association, Montreal, Quebec, Canada. [Online]. Available at http://cpsquare.org/wp-content/uploads/2008/07/stuckey-etal-aera-sna.pdf. [Accessed May 1st 2012].

Moon, J. A. (1999). Reflection in Learning and Professional Development: Theory and Practice. London: Kogan Page Inc.

Reffay, C., \& Chanier, T. (2003). How Social Network Analysis Can Help to Measure Cohesion in Collaborative Distance-Learning. Computer Supported Collaborative Learning. Bergen: Kluwer Academic Publishers. [Online]. Available at http://edutice.archives-ouvertes.fr/docs/00/00/19/14/PDF/reffay_chanier. pdf. [Accessed May 1st 2012].

Rowland, S. (2001). Surface Learning about Teaching in Higher Education: the Need for More Critical Conversations. International Journal for Academic Development, 6(2), 162-167.

\section{Author Biographies}

Dr Hanna Yakavenka is a principal lecturer and MBA/MA International Business programme director at the University of Greenwich Business School. Her recent research has been in the field of learning and professional development, where she has particularly focusing on peer learning and its effects on academic performance.

Dr Riccardo De Vita is a senior lecturer and BA Hons International Business programme leader at the University of Greenwich Business School. His recent research has focused on the application of Social Network Analysis to online communities 
